\title{
Gamma-M Deficiency Predisposing to Meningococcal Septicaemia
}

\author{
J. R. HOBBS,* M.D., B.SC., M.R.C.P., M.C.PATH.; R. D. G. MILNER, *† M.A., M.B., M.R.C.P. \\ P. J. WATT, $* \ddagger$ M.B., M.R.C.P.
}

Brit. med. F., 1967, 4, 583-586

Before his death from cerebrospinal fever Dr. G. D. Heist showed that he was one of the rare individuals whose blood had no bactericidal action on meningococci (Heist et al., 1922). His father and four uncles also died of illnesses resembling meningococcal infections. We have observed two patients with fulminating meningococcal septicaemia who had abnormally low serum $\gamma \mathrm{M}$ globulins. Noting the susceptibility of Dr. Heist and possibly his family to meningococcal infections, and the possibility of a causal relation between a deficiency of serum $\gamma \mathrm{M}$ globulin and meningococcal infection, we carried out a survey of the immunoglobulin levels in the relatives of our two patients and made a study of antibodies to meningococci.

\section{Propositi}

\section{Subjects}

The immunoglobulin levels of five children suffering from meningococcal meningitis or septicaemia were studied. Brief summaries of their case histories are shown below.

Case 1.-An 8-year-old West Indian boy was admitted in a state of shock with an ecchymotic rash which had started 12 hours earlier. Waterhouse-Friderichsen syndrome was diagnosed, and treatment with intravenous antibiotics, hydrocortisone, and plasma expanders started immediately, but he became comatose and died four hours later. Before treatment started the plasma cortisol level was 61 $\mu \mathrm{g} . / 100 \mathrm{ml}$. and the neutrophil count $9,000 / \mathrm{cu}$. mm., with a marked left shift. Meningococci were isolated from blood cultures. Necropsy revealed bilateral haemorrhagic necrosis of the adrenals, fibrin occlusion of subcutaneous and dermal vessels with haemorrhage into the dermis, pulmonary congestion, and oedema.

Case 2.-A 5-year-old boy was admitted because of generalized convulsions, neck stiffness, and a fever of $107.4^{\circ} \mathrm{F}$. $\left(41.9^{\circ} \mathrm{C}\right.$. $)$ which had begun eight hours earlier. Cerebrospinal fluid was normal and antipyretics were effective initially, but eight hours later hyperpyrexia returned accompanied by coma and a purpuric rash. A diagnosis of meningococcaemia was made and was later confirmed by blood culture. The neutrophil count was $5,000 / \mathrm{cu}$. $\mathrm{mm}$. and showed an extreme left shift. Despite treatment he died two hours later. The plasma cortisol level just before treatment with corticosteroids was $208 \mu \mathrm{g} . / 100 \mathrm{ml}$. Necropsy revealed no important abnormality apart from purpura.

Case 3.-This patient was a first cousin of Case 2. When 4 weeks old and asymptomatic she was found to have normal immunoglobulin levels for her age during screening of the relatives of Case 2. At the age of 9 weeks she was admitted because of neck stiffness and fever. The neutrophil count was 7,000/cu. mm., with a marked left shift. Blood and C.S.F. cultures grew meningococci. She responded to antibiotic therapy and made a complete recovery.

Case 4.-An 11-month-old girl was admitted because of a twoday history of fever and neck stiffness. Her blood showed a neutrophilia with a left shift. Meningococci were grown from both blood and C.S.F. cultures. Chemotherapy resulted in a slow but complete and uneventful recovery.

Case 5.-An 8-week-old baby was admitted because of fever which had not responded to penicillin. Examination showed a

\footnotetext{
* Royal Postgraduate Medical School and Institute of Child Health, Hammersmith Hospital, London W.12.

† Present address : Department of Biochemistry, University of Cambridge.

‡ Present address: The Wright-Fleming Institute of Microbiology, St. Mary's Hospital Medical School, London $\mathbb{W} .2$.
}

petechial rash and a bulging anterior fontanelle. The C.S.F. contained moderate numbers of neutrophils, some of which contained Gram-negative diplococci, glucose $35 \mathrm{mg} . / 100 \mathrm{ml}$., and protein $335 \mathrm{mg} . / 100 \mathrm{ml}$., but yielded no bacterial growth. A clinical diagnosis of meningococcal meningitis was made, and with intensive chemotherapy she recovered completely.

\section{Families}

A survey of the immunoglobulin levels of all the available relatives of Cases 1 and 2 was carried out shortly after the death of these patients. The parents of Case 5 had normal immunoglobulin levels, but both the mother and father of Case 4 had $\gamma \mathrm{M}$ levels of $30 \mathrm{mg} . / 100 \mathrm{ml}$. with normal $\gamma \mathrm{G}$ and $\gamma$ A levels.

\section{Positive Controls}

Sera taken from four patients (A, B, C, and D) two to three weeks after the onset of meningococcal meningitis were kindly supplied by the Standards Reference Laboratory, Colindale, and were tested for meningscoccal antibodies and immunoglobulin levels.

\section{Normal Sera}

Pooled serum from 10 mothers and pooled cord serum from their babies were tested for bactericidal action on meningococci under varying conditions. Cord serum contains half the adult level of haemolytic complement (Ewald et al., 1961), has the same $\gamma \mathrm{G}$ content, but is deficient in $\gamma \mathrm{A}$ and $\gamma \mathrm{M}$.

\section{Idiopathic Isolated $\gamma M$ Deficiency}

Serum immunoglobulin levels were measured in over 3,000 miscellaneous hospital patients. Among 350 patients with deficiencies most had subnormal levels of $\gamma \mathrm{G}, \gamma \mathrm{A}$, and $\gamma \mathrm{M}$ all together. However, in 76 patients subnormal levels of $\gamma \mathrm{M}$ globulin occurred alone. In 47 of these the abnormality was thought to be secondary to pre-existing diseases such as myelomatosis, chronic lymphatic leukaemia, lymphoma, renal failure, idiopathic steatorrhea, etc. In 29 patients there was no known predisposition. Of these, 18 were asymptomatic, but among 11 who were symptomatic were three of the propositi (Cases 1,2, and 4), two with pneumococcal meningitis, one with Escherichia coli meningitis, one with recurrent $E$. coli pyelonephritis, and four with mixed respiratory infections. Bacteraemia was proved in 10 of these 11 patients.

\section{Methods}

Immunoglobulin Measurements.-Immunoglobulin levels were measured by a modified Mancini method (Goldman and Hobbs, 1967). All sera were separated at $37^{\circ} \mathrm{C}$. and when possible tested the same day to avoid loss of $\gamma \mathrm{M}$. Aliquots were stored at $-20^{\circ} \mathrm{C}$, thawed once only for tests, and then discarded. Our own log-normal ranges are given for adults and throughout childhood in Tables I and II. In the families 
of Cases 1 and 2 some sera showed low or borderline $\gamma \mathrm{M}$ levels. After ABO grouping of the red blood cells of such relatives of Case 1, isoantibody titres were measured as one way of assessing the quality of what little $\gamma \mathrm{M}$ globulin the subject had.

Meningococcal Antibodies.-Antibodies to meningococci were sought by the indirect fluorescence method. In Cases 2, 3 , and 4 the organisms grown from the patient were tested against the patient's serum. Otherwise serum or C.S.F. was tested against four strains of meningococci-groups $\mathrm{A}$ and $\mathrm{B}$, a non-groupable strain isolated from Case 2, and the strain isolated from Case 4. Air-dried smears of the organisms were exposed to the serum or C.S.F. to be tested, washed, then exposed to fluorescent rabbit antisera monospecific for human $\gamma \mathrm{G}, \gamma \mathrm{A}$, or $\gamma \mathrm{M}$ globulin and finally washed. Results were graded as negative $(0)$ or positive $(+,++,+++)$. Rabbit $\gamma$-globulin fractions were conjugated to both fluorescein and lissamine rhodamine B200. The specificity and efficacy of the antisera had been verified many times on human myeloma marrow samples, etc.

Complement-fixation Tests.-Meningococci of groups A and $B$ and of a non-groupable strain were grown as shake cultures in brain-heart infusion broth enriched with $20 \%$ horse serum. Antigens were extracted by a modified Price method (Ross and Stevenson, 1962), and complement fixation was tested as described by Ross (1961).

Bactericidal Activity of Sera.-Two pools of maternal and umbilical cord serum were treated by adsorbing lysozyme and $\beta$-lysin on to bentonite (Muschel and Jackson, 1966). Complement was inactivated by heating the serum to $56^{\circ} \mathrm{C}$. for 30 minutes. The bactericidal activity of the unabsorbed, absorbed, and heated serum was tested by adding $3 \times 10^{5}$ meningococci to $1 \mathrm{ml}$. of serum and performing duplicate pour-plate counts at $5,10,20,40$, and 60 minutes thereafter.

\section{Results}

Table I summarizes the immunoglobulin levels and the results of meningococcal fluorescent antibody and complement- fixation tests in the nine patients who suffered meningococcal infection. In the fatal cases (Nos. 1 and 2) and in the patient who survived (Case 4), the $\gamma M$ serum levels were subnormal at the start of the illness, and in Cases 3 and 5 and the positive control $\mathrm{A}$ the $\gamma \mathrm{M}$ was low because they were only 2 months old. Case 4 had low serum $\gamma \mathrm{A}$ levels during the acute illness and convalescence. During convalescence $\gamma \mathrm{G}$ or $\gamma \mathrm{M}$ meningococcal antibodies appeared in the serum of survivors and a complement-fixation test was positive in Case 4 and all of the positive controls. In Case 5, the only patient from whom meningococci were not cultured, the nature of the bacterial meningitis was confirmed by the presence of $\gamma \mathrm{M}$ antibodies to meningococci in both serum and C.S.F. during convalescence. Neutropenia, commonly associated with septicaemia, was not present in the five propositi in whom phagocytosis appeared to be normal.

The family trees of the relatives of Cases 1 and 2 are shown in Figs. 1 and 2 respectively. The father, paternal uncle, and
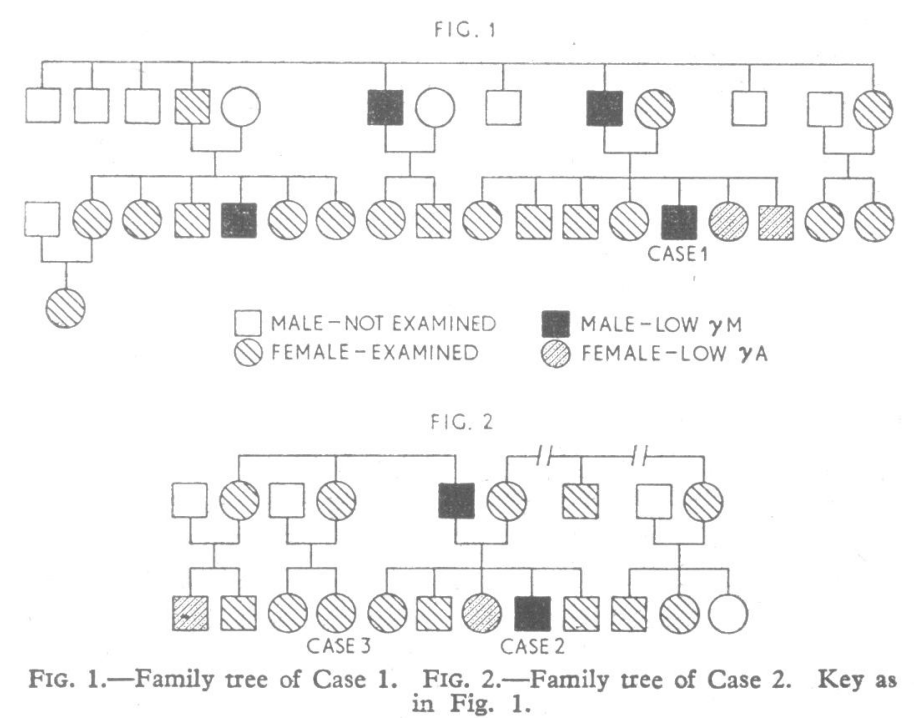
in Fig. 1.

TABLE I.-Immunoglobulin Levels, Meningococcal Antibodies, and Meningococcal Complement-fixation Tests in Propositi and Positive Controls. Normal Ranges of Serum Immunoglobulins $\pm 2 S . D$. are Shown in Parentheses

\begin{tabular}{|c|c|c|c|c|c|c|c|c|c|c|c|}
\hline & \multirow{2}{*}{$\begin{array}{c}\text { Age } \\
\text { in } \\
\text { Years }\end{array}$} & \multirow{2}{*}{$\begin{array}{c}\text { Sample and Time } \\
\text { of Collection } \\
\text { After Onset } \\
\text { of } \\
\text { Infection }\end{array}$} & \multicolumn{3}{|c|}{ Immunoglobulins (mg. $/ 100 \mathrm{ml}$.) } & \multicolumn{3}{|c|}{$\begin{array}{l}\text { Meningococcal Fluorescent } \\
\text { Antibody }\end{array}$} & \multicolumn{3}{|c|}{$\begin{array}{l}\text { Meningococcal Complement- } \\
\text { fixation Test }\end{array}$} \\
\hline & & & $\gamma \mathrm{G}$ & $\gamma \mathrm{A}$ & $\gamma \mathbf{M}$ & $\gamma \mathrm{G}$ & $\gamma \mathrm{A}$ & $\gamma \mathbf{M}$ & $\underset{\text { A }}{\text { Group }}$ & $\underset{\text { B }}{\text { Group }}$ & $\underset{\text { Noun- }}{\text { Noupable }}$ \\
\hline $\begin{array}{rrr}\text { Case } & 1 & \ldots \\
& 2 & \ldots \\
& 3 & \\
. & 3 & \end{array}$ & $\begin{array}{c}810 / 12 \\
52 / 12 \\
4 / 52 \\
9 / 52 \\
10 / 12 \\
11 / 12\{\end{array}$ & 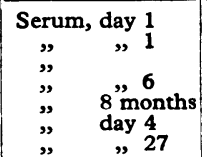 & $\begin{array}{c}560(600-1,600) \\
1,120(600-1,600) \\
480(350-900) \\
400(200-700) \\
600(300-1,300) \\
350(300-1,300) \\
300(300-1,300)\end{array}$ & $\begin{array}{l}70(65-250) \\
190(55-215) \\
40(5-40) \\
70(8-45) \\
60(25-95) \\
<2(25-95) \\
19(25-95)\end{array}$ & $\begin{array}{r}4(50-170) \\
12(50-170) \\
25(10-40) \\
130(15-150) \\
100(50-170) \\
21(50-170) \\
50(50-170)\end{array}$ & $\begin{array}{r}0 \\
0 \\
0 \\
0 \\
+ \\
0 \\
++\end{array}$ & $\begin{array}{l}\mathbf{0} \\
0 \\
0 \\
0 \\
0 \\
0 \\
0\end{array}$ & $\begin{array}{l}0 \\
0 \\
0 \\
0 \\
+ \\
0 \\
0\end{array}$ & $\begin{array}{c}0 \\
0 \\
0 \\
0 \\
0 \\
1 / 16\end{array}$ & $\begin{array}{r}0 \\
0 \\
0 \\
0 \\
0 \\
1 / 32\end{array}$ & $\begin{array}{c}0 \\
0 \\
0 \\
0 \\
0 \\
1 / 32\end{array}$ \\
\hline 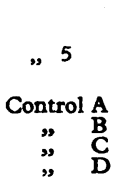 & $\begin{array}{c}8 / 52 \\
2 / 12 \\
7 \\
17 \\
37\end{array}$ & 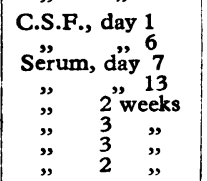 & $\begin{array}{l}70 \\
50 \\
230(200-700) \\
290(200-700) \\
300(200-700) \\
600(600-1,600) \\
800(600-1,600) \\
960(600-1,600)\end{array}$ & $\begin{array}{l}<1 \\
<1 \\
7(8-45) \\
7(8-45) \\
<15(8-45) \\
160(60-240) \\
180(125-425) \\
300(125-425)\end{array}$ & $\begin{array}{l}<1 \\
25 \\
53(15-50) \\
28(15-50) \\
50(15-50) \\
120(50-170) \\
90(50-170) \\
100(50-170)\end{array}$ & $\begin{array}{c}0 \\
0 \\
0 \\
0 \\
+ \\
0 \\
+++ \\
++\end{array}$ & $\begin{array}{l}0 \\
0 \\
0 \\
0 \\
0 \\
0 \\
0 \\
0 \\
0\end{array}$ & $\begin{array}{c}0 \\
++ \\
0 \\
++ \\
0 \\
++ \\
0 \\
+\end{array}$ & $\begin{array}{c}0 \\
1 / 8 \\
1 / 8 \\
1 / 128 \\
1 / 128\end{array}$ & $\begin{array}{c}0 \\
1 / 32 \\
1 / 16 \\
1 / 128 \\
1 / 128\end{array}$ & $\begin{array}{c}0 \\
1 / 4 \\
1 / 4 \\
1 / 256 \\
1 / 128\end{array}$ \\
\hline
\end{tabular}

TABLE II.-Cases 1 and 2 and Their Relatives with Abnormal Immunoglobulin Levels, ABO Isoantibody Titres of Relatives of Case 1 with Low $\gamma M$ Levels. Normal Ranges of Serum Immunoglobulins $\pm 2 S . D$. are Shown in Parentheses

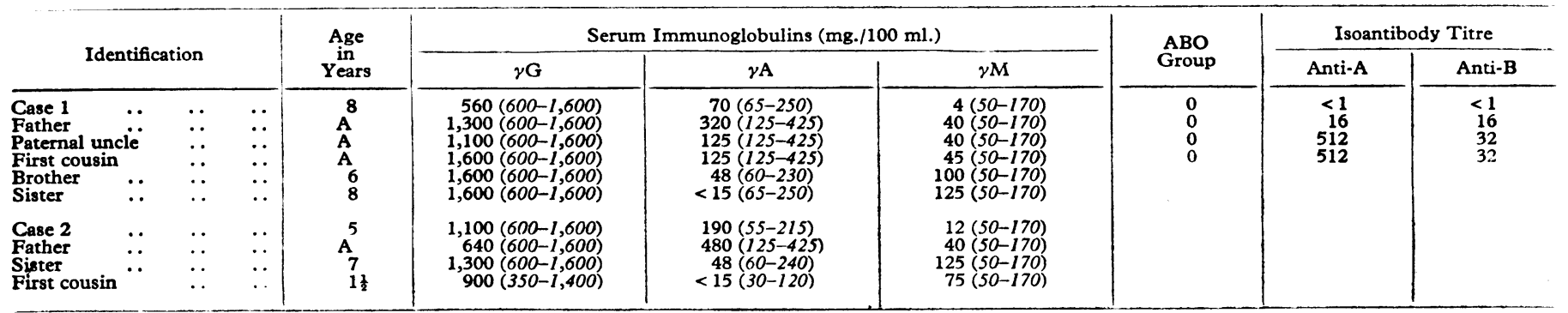


paternal first cousin of Case 1 and the father of Case 2 had $\gamma \mathrm{M}$ levels more than 2 S.D. below our normal range (Table II) but were asymptomatic and had uneventful past histories. Two siblings of Case 1 and a sibling and first cousin of Case 2 had abnormally low serum $\gamma \mathrm{A}$ levels. Case 1 had a lower titre of ABO isoantibodies than his relatives with low $\gamma M$ levels (Table II).

The bactericidal activity of normal serum to meningococci was investigated with pooled maternal or umbilical cord serum. The destruction of complement by heating removed bactericidal activity to meningococci. Fig. 3 shows that umadsorbed umbilical cord serum had a moderate bactericidal activity but that this disappeared after the adsorption of lysozyme and $\beta$-lysin. Maternal serum, on the other hand, had a much greater bactericidal activity, which was only slightly lessened after adsorption of the serum.

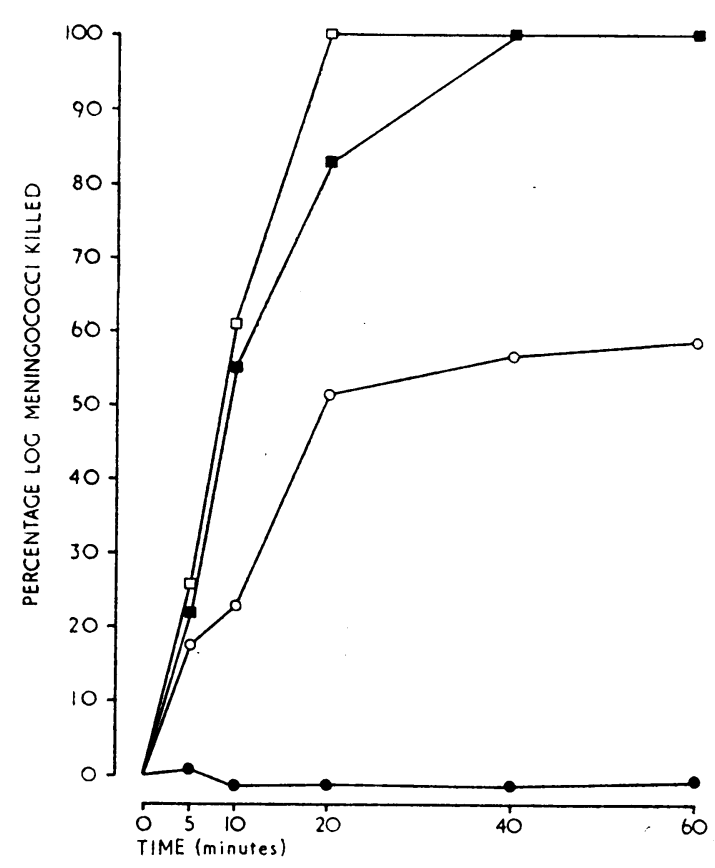

FIG. 3.-Bactericidal activity to meningococci of pooled maternal (squares) or cord serum (circles). Results from
unadsorbed serum are shown by open symbols and from serum after bentonite adsorption by solid symbols.

\section{Discussion}

The observation that two boys who died from the Waterhouse-Friderichsen syndrome had a deficiency of serum $\gamma \mathrm{M}$ globulin led to an investigation of the role of $\gamma \mathrm{M}$ globulin as a humoral defence mechanism against meningococci. Neither of the boys died from acute adrenal failure, for plasma cortisol levels shortly before death were normal or raised. Neutropenia was not responsible for the rapid multiplication of meningococci, and in the case of Dr. Heist normal phagocytosis of meningococci was observed. It was postulated that the fulminating meningococcal septicaemia was due to a lack of bactericidal antibody and that death probably resulted from endotoxaemia or a generalized Schwartzman reaction. The postmortem finding of fibrin occlusion of small vessels in Case 1 was in keeping with the view that death in a generalized Schwartzman reaction may be due to widespread intravascular coagulation (Skjörten, 1966).

Immunoglobulin levels and meningococcal antibodies were studied in three children admitted to hospital suffering from meningococcal meningitis and in the sera of four patients who were convalescing from meningococcal meningitis. None of the three children had meningococcal antibodies on admission to hospital, but $\gamma M$ and/or $\gamma \mathrm{G}$ antibodies were detected in all seven patients during convalescence. In a 2-month-old baby (Case 5) $\gamma M$ meningococcal antibodies were found in the C.S.F. on the sixth but not on the first day after admission. Normally, $\gamma \mathrm{M}$ is not present in the C.S.F. (Schultze and Heremans, 1966), and the finding of C.S.F. $\gamma M$ antibody in one patient suggested that the concentration had risen either as a result of active transport of $\gamma \mathrm{M}$ across the blood-brain barrier or, more likely, by secretion from cells which had migrated into the subarachnoid space. It was thought unlikely that $\gamma \mathrm{M}$ (mol. wt. $1,000,000$ ) had entered the C.S.F. by simple diffusion, for it was present at half the serum concentration whereas $\gamma \mathrm{G}$ (mol. wt. 160,000) was present at one-fifth the serum concentration.

The detection of both $\gamma \mathrm{G}$ and $\gamma \mathrm{M}$ meningococcal antibodies prompted a study of the meningococcidal activity of normal maternal and umbilical cord serum. The cord serum had the same $\gamma \mathrm{G}$ as the maternal serum but negligible amounts of $\gamma \mathrm{A}$ or $\gamma \mathrm{M}$.

The meningococcidal activity of both adult and cord serum was dependent on complement, but the activity of adult serum was not greatly affected by bentonite adsorption of lysozyme and $\beta$-lysin (Fig. 3). The weaker activity of cord serum was completely abolished after bentonite adsorption. This suggested that the meningococcidal activity of adult serum did not reside in $\gamma \mathrm{G}$ globulin, and since fluorescence had failed to detect $\gamma \mathrm{A}$ antibodies the evidence favoured $\gamma \mathrm{M}$ as the site of meningococcidal activity. Bactericidal antibodies against other Gramnegative organisms have been found mainly in the $\gamma \mathrm{M}$ fraction of the serum (Michael and Rosen, 1963 ; Evans et al., 1966) and are absent in the $\gamma \mathrm{A}$ fraction (Adinolf et al., 1966).

Cohen and Norins (1966) demonstrated by immunofluorescent techniques that there were natural antibodies to $E$. coli and Neisseria gonorrhoeae in the $\gamma \mathrm{A}, \gamma \mathrm{G}$, and $\gamma \mathrm{M}$ fractions of normal serum and suggested that $\gamma \mathrm{G}$ antibodies had a critical role in the bacterial recognition system of the host. However, in a prospective study Sample et al. (1966) showed that prophylactic pooled human gammaglobulin (virtually only $\gamma \mathrm{G}$ globulin) offered no protection against the development of meningococcal meningitis and septicaemia.

In a study of the epidemiology of meningococcal infection more than $90 \%$ of Army recruits entering a training camp were found to become nasopharyngeal carriers of the endemic group B meningococcus (Brown and Condit, 1965). Despite the almost universal colonization of the upper respiratory tract of recruits entering an endemic area, only 1 in 400 got systemic disease, and of these only $10 \%$ had fulminating meningococcaemia. It is possible that the very small percentage of people who develop fulminating meningococcaemia lack an effective system for destroying meningococci in the blood stream which may be $\gamma \mathrm{M}$ globulin. The colonization of the nasopharynx by meningococci in most of the recruits suggests that $\gamma \mathrm{A}$ globulin, the immunoglobulin which normally protects mucus surfaces (South et al., 1966), does not afford protection against meningococci. Our failure to detect $\gamma \mathrm{A}$ antibodies to meningococci is in keeping with this suggestion, which also lends support to the theory that meningococci gain access to the C.S.F. via the cribriform plate.

In the retrospective survey of immunoglobulin levels in over 3,000 hospital patients, 29 had an idiopathic isolated $\gamma \mathrm{M}$ deficiency. A third of these had proved bacteraemia, confirming the importance of $\gamma \mathrm{M}$ antibody in blood-stream defence. Further, pronounced increases in $\gamma \mathrm{M}$ levels occur in infections mainly confined to the blood stream such as malaria, trypanosomiasis (Mattern et al., 1961), bartonellosis, and rickettsial endocarditis (Hobbs et al., 1967b).

The discovery that the fathers of the two fatal cases and two male relatives of Case 1 also had $\gamma M$ deficiency suggested that the abnormality might be inherited. This could offer an explanation of why Heist, whose blood had no meningococcidal activity, and his five male relatives, all died of illnesses resembling cerebrospinal fever. 
This isolated and severe $\gamma \mathrm{M}$ deficiency can be classified as a dysgammaglobulinaemia. It is distinct from the GiedionScheidegger variety (type 1), where $\gamma \mathrm{A}$ is also very low and where there is a continual history of all kinds of bacterial infections from birth. Case 4 initially showed a low $\gamma \mathrm{A}$ and $\gamma \mathrm{M}$, but this may have been due to delay in immunological maturation, for both are now developing normally. Cases 1 and 2 are also distinct from the Wiskott-Aldrich syndrome (type VA), a sex-linked recessive condition usually fatal to affected males before 10 years of age, where though $\gamma \mathrm{M}$ deficiency appears it is usually associated with a marked increase of $\gamma \mathrm{A}$. Clinically there is a long history of eczema, thrombocytopenia, and recurrent infections from soon after birth. Cases 1 and 2 have therefore been classified as type VB by Hobbs et al. (1967a). Furthermore, it is realized that isolated deficiency of $\gamma \mathrm{M}$ can be found in apparently healthy subjects (type VO) and can be associated with defects of other classes of immunoglobulins in both sexes of given families (Burtin et al., 1964). Thus the finding of $\gamma \mathrm{A}$ deficiency in four other relatives of Cases 1 and 2 adds support to a genetic basis for their fatal abnormality.

\section{Summary}

Serum immunoglobulin levels and meningococcal antibodies were measured in nine patients suffering from meningococcal infection. The bactericidal activity of normal serum to meningococci could be attributed largely to $\gamma \mathrm{M}$ globulin. Severe $\gamma \mathrm{M}$ deficiency, probably inherited, was found in two boys dying from fulminating meningococcal septicaemia. Other evidence supported the view that $\gamma \mathrm{M}$ antibodies are an important humoral defence mechanism and that the normal presence of these antibodies in the blood stream restrains systemic meningococcal infection to the C.S.F.

We thank Professor J. P. M. Tizard and Dr. J. A. Davis for allowing us to study patients under their care; Dr. S. Worlledge, who estimated the blood groups and isoantibody titres; and Professor L. P. Garrod for his advice. Requests for reprints should be addressed to Dr. J. R. Hobbs, Department of Chemical Pathology, the Royal Postgraduate Medical School, Ducane Road, London W.12.

\section{REFERENCES}

Adinolf, M., Glynn, A. A., Lindsay, M., and Milne, C. M. (1966). Immunology, 10, 517

Brown, J W. and Condit, P. K. (1965). Calif. Med., 102, 171. Burtin, P., Buffe, D., and Grabar, P. (1964). Ann. Inst. Pasteur, 106, 519.

Cohen, I. R., and Norins, L. C. (1966). Science, 152, 1257.

Evans, R. T., Spaeth, S., and Mergenhagen, S. E. (1966). F. Immunol., 97,112 .

Ewald, R. A., Williams, J. H., and Bowden, D. H. (1961). Vox Sang. (Basel), 6, 312 .

Goldman, J. M., and Hobbs, J. R. (1967). Immunology, 13, 421.

Heist, G. D., Solis-Cohen, S., and Solis-Cohen, M. (1922). 7. Immunol., $7,1$.

Hobbs, J. R., Russell, A., and Worlledge, S. M. (1967a). Clin. exp. Immunol., 2, 589 .

Immunol, 2, s89. A, and McSwiggan, D. A. (1967b). Lancet, 1 , 1108 .

Mattern, P., Masseyeff, R., Michel, R., and Peretti, P. (1961). Ann. Inst. Pasteur, 101, 382.

Michael, J. G., and Roven. F. S. (1963). F. exp. Med., 118, 619.

Muschel. L. H., and Jackson, J. E. (1966). F. Immunol., 97, 46.

Ross, C. A. C. (1961). Lancet, 2, 527.

- and Stevenson, J. (1962). F. Hyg. (Lond.), 60, 501.

Sample, D W Gauld, J. R., Warram, J. H. Winter, P. E., Runcik, K., and Go Gauld, (1966). Amer. I. Epidem. 84, 156.

Schultze, H. E., and Heremans, J. F. (1966). The Molecular Biology of Human Proletns, 1, 737 . London.

Skiörten F (1966). Acia pain microbiol. scand., 68, 517.

Skiörten. F. (1966). Acta pain microhiol. scand., 6 , Wong, R., and Good, R. A. (1966). J. exp. Med., 123, 615 .

\title{
Access to Circulation by Permanent Arteriovenous Fistula in Regular Dialysis Treatment*
}

\author{
J. S. HANSON, M.B., B.SC. ; M. CARMODY, M.B. ; B. KEOGH, M.B. ; W. F. O'DWYER, M.D.
}

Brit. med. F., 1967, 4, 586-589

Regular dialysis therapy has now become the accepted treatment of selected cases with end-stage renal disease.

Heretofore, repeated access to blood vessels for dialysis was achieved by means of the conventional Teflon or Teflon-Silastic prosthesis, establishing an external semipermanent arteriovenous shunt (Quinton et al., 1960, 1962 ; Hegstrom, 1961). In spite of its considerable success this technique is far from perfect, and problems of infections and clotting remain as a major cause of trouble in the management of these patients. The average survival rate for external shunts varies considerably from one centre to another. In a series published from the Swedish Hospital in Seattle the mean shunt life for both arteries and veins varied from 11 days to 11.4 months (Murray et al., 1964). In a more recent review from the same cenrre (Pendras and Smith, 1966) an average cannula survival of 12 to 14 months was reported. This they attributed to the prevention of infection in the patient before and shortly after operation, and also by avoiding cannulation in the severely uraemic state.

We have been unable to achieve a similar standard of shunt survival since we began regular dialysis therapy in November 1964. Our survival rates in arteries and veins were 3.8 and 3.6 months respectively, the majority of the failures occurring

- Department of Surgery and Renal Unit, Jervis Street Hospital, Dublin. in the first six weeks after surgery. The longest surviving shunt was 16 months. Infection and clotting, the major causes of our failures, were responsible for a high morbidity and often long periods of immobilization in hospital for surgical revision of the cannulas. This was particularly true for those in the lower limbs. The frequent manipulations involved in declotting were also a contributory factor to the psychological fixations which some of these patients developed about their cannulas. Our relative failure with the Quinton type shunt prompted us to adopt the surgically created arteriovenous fistula as described by Brescia et al. (1966). As a result of the arteriovenous fistula so created the arm veins are distended, allowing dialysis to be carried out by venepuncture. The veins are then in effect an extension of the arterial system.

\section{Surgical Technique}

Anaesthetic.-Brachial plexus block by the axillary route has been used routinely and has proved very satisfactory. Firstly, the accompanying sympathetic block dilates the blood vessels and prevents vascular spasm until the vein has been denervated by the stripping of its fascia. The sympathetic blockage may lead to free bleeding from the line of incision, but 